\title{
WEB-BASED IRRIGATION MONITORING AND CONTROL SYSTEM
}

\author{
Wodadaya Nafutali, Semwogerere Twaibu, Matovu Davis, \\ Lusiba Badru and Gilbert Gilibrays Ocen
}

Department of Computer Engineering, Busitema University, Uganda

\begin{abstract}
In Uganda, as well as other developing countries, the increasing population stimulates the agricultural-related activities such as irrigation. Irrigation is basically done by humans and generally requires exhaustive physical efforts and involves exposure to errors during irrigation. Despite the advances in the irrigation and its wide spreading applications, irrigation remains majorly manual. Since irrigating is a difficult process especially when irrigating a big piece of land, it is necessary to simplify the process, thus web based system in irrigating was introduced and existing implementations have limitations such as irrigating at wrong hours, continued wastage of water, so prevent all this, a new system that uses a web control to remotely irrigate from a distance has been developed, therefore main objective of this project is to design and develop a web based irrigation monitoring and control system since it is observed that this method is more reliable and efficient compared to the existing methods. The developed system is able to automatically receive the moisture levels from the field, responds to the different commands sent by the user to do the irrigation and the user is also able to switch on and off the pump.
\end{abstract}

\section{KEYWORDS}

Ethernet Shield, Irrigation System, Microcontroller, Sensors, Web based system.

\section{INTRODUCTION}

\subsection{Back Ground}

Agriculture plays a vital role in the development of country's economy; the daily need for food shows the importance of agricultural development. Growing a particular crop in a particular region takes the privilege of monitoring the growth from cultivation until harvesting. One of the main challenges in agricultural activities is irrigation [1]. As the global climate has decreased the source of water throughout the world, it is necessary to take steps for preserving it. However, the people themselves do traditional irrigation management which requires the presence and continuous monitoring of irrigation by the farmers in the field area to check whether the farmland has received sufficient amount water [2]. The user must need to manually change the direction of water flow using large pipes in the field here it creates a need for more labor work and maintenance.

The agricultural systems in developing countries are still labor dependent and do not use any crop management, pest/disease control or quality management systems. The traditional irrigation systems in agriculture use uniform water distribution in fields at regular intervals, which is not optimal. Hence, a technology based agricultural monitoring system which decides itself intelligently and performing the action is needed [3]. Water management is one of the most important tasks in agriculture and efficient water management is a major concern in many cropping systems in semiarid and arid areas [4]. However, the farmers rely on their intuition and 
International Journal of Computer Science, Engineering and Information Technology (IJCSEIT), Vol.11, No.1/2/3/4/5/6, December 2021

experience to determine when and how much water should be provided. Sensing technologies have been highly developed and several test works were conducted.

Precision agriculture (PA), as the name implies, refers to the application of precise and corrects amounts of inputs like water, at the correct time to the crop for increasing its productivity and maximizing its yields and since now days sensor technologies are very much helpful in creating the smart précised environment and this technology has created a new way of research in the field of agriculture [5]. A precise decision or action on water supply for a particular area for cop production is very critical in precision agriculture practices [6]

However the existing implementations have limitations in that they made farmland not receive the required amount of water for example systems like manual method, Bluetooth based irrigation system are unreliable therefore there is need for the implementation of web based irrigation monitoring and control system.

The existing method and one of the oldest ways in agriculture is the manual method of checking the parameters. In this method the farmers they themselves verify all the parameters and calculate the readings. It focuses on developing devices and tools to manage, display and alert the users using the advantages of a wireless sensor network system, the Bluetooth wireless transmitters sense the information regarding soil moisture and the time specific decision for irrigation is made according to the information sensed. Base station in turn sends control signals to the irrigation control station to operate the device for water usage. However this is limited with the distance since it works in short range therefore it's not a reliable method [7].

The implemented system is a web-based irrigation monitoring and control system. This will consider the drawbacks of the existing related irrigation monitoring and control systems. The system will be will installed in the field, the system will be able to detect the soil moisture levels and store it on the online database. The stored data will be presented to the user in the web dash board, the system will remotely monitor the moisture levels in the field then take a decision whether to irrigate or not.

\subsection{Related Work}

There are several automated irrigation systems that have been developed to assist farmers on the globe. These were summarized in Table 1 by looking at their merits and demerits to support the system built and explained. 
International Journal of Computer Science, Engineering and Information Technology (IJCSEIT),

Vol.11, No.1/2/3/4/5/6, December 2021

Table 1. Comparison of the Existing Systems [4] \& [8]

\begin{tabular}{|c|c|c|}
\hline Existing Systems & Working/Merits & Drawbacks \\
\hline Manual Irrigation System & $\begin{array}{l}\text { Farmers verify all the } \\
\text { parameters and calculate the } \\
\text { readings themselves. There is } \\
\text { high level of reliability and it is } \\
\text { also cheap. }\end{array}$ & $\begin{array}{l}\text { It is bound to errors since the } \\
\text { farmer checks manually if there } \\
\text { is need for irrigation or not. }\end{array}$ \\
\hline $\begin{array}{l}\text { GSM-Based Automatic } \\
\text { Irrigation Control System }\end{array}$ & $\begin{array}{l}\text { Through an SMS, the user } \\
\text { sends activation command to } \\
\text { the system, checks the moisture } \\
\text { level and start the motor or } \\
\text { otherwise. It is asily accessed } \\
\text { from anywhere. }\end{array}$ & $\begin{array}{l}\text { The system is limited in that the } \\
\text { farmer may not receive the } \\
\text { message alert in time for some } \\
\text { reason. }\end{array}$ \\
\hline $\begin{array}{l}\text { Irrigation Monitoring and } \\
\text { Control using Bluetooth } \\
\text { Technology }\end{array}$ & $\begin{array}{l}\text { Bluetooth wireless transmitters } \\
\text { sense the information regarding } \\
\text { soil moisture and the time } \\
\text { specific decision for irrigation } \\
\text { is made. Limited with the } \\
\text { distance (works in short range). }\end{array}$ & $\begin{array}{l}\text { This system is limited with the } \\
\text { distance since it works in short } \\
\text { range. }\end{array}$ \\
\hline $\begin{array}{l}\text { Micro-Controller } \quad \text { Automatic } \\
\text { Irrigation System }\end{array}$ & It can be easily accessed & It is slow in delivery \\
\hline
\end{tabular}

\section{MethodS AND MATERIALS}

\subsection{Hardware Used Microcontroller}

The microcontroller is one of the most popular microcontrollers in the industry. It is user convenient and easier to handle. The coding or programming of this controller is also easy. The program that is coded can be easily erased due to the flash memory technology. The microcontroller has wide range of applications used in many huge industries. It is used insecurity, remote sensors, home appliances and industrial automations [9]. An EEPROM is also featured which is used to store the information permanently like transmitter codes and receives frequencies and some other related data.

\section{Moisture Sensor}

Soil moisture sensor is a sensor which senses the moisture content of the soil [10]. The sensor has both the analog and the digital output. The digital output is fixed and the analog output threshold can be varied. It works on the principle of pen and short circuit. The output is high or low indicated by the LED. When the soil is dry, the current will not pass through it and so it will act as an open circuit. Hence the output is said to be maximum. When the soil is wet, the current will pass from one terminal to the other and the circuit is said to be short and the output will be zero. 
International Journal of Computer Science, Engineering and Information Technology (IJCSEIT), Vol.11, No.1/2/3/4/5/6, December 2021

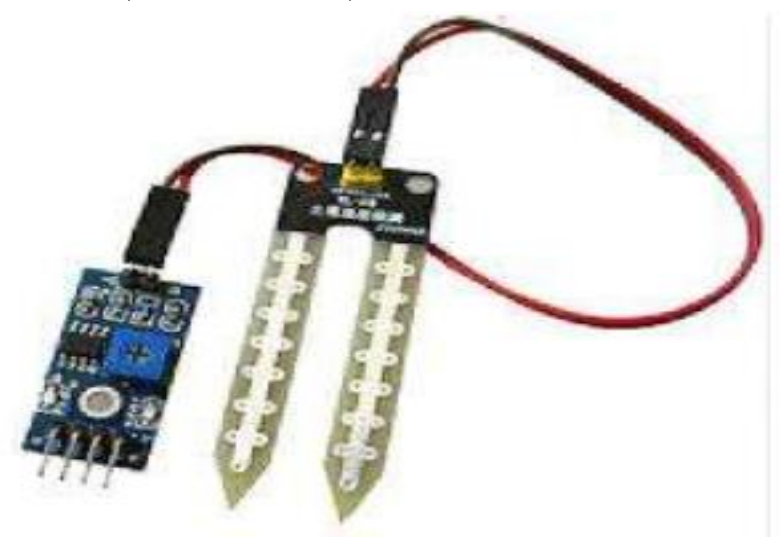

Figure 1. Moisture Sensor

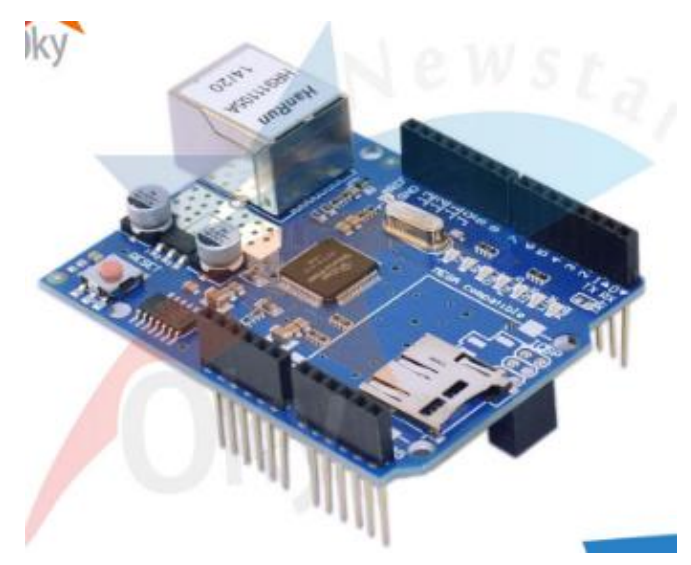

Figure 2. The Ethernet Shield

It is based on the Wiznet W5500 Ethernet chip [10]. The Wiznet W5500 provides a network (IP) stack capable of both TCP and UDP. It supports up to eight simultaneous socket connections. The Ethernet Shield to connect to an Arduino Board using long wire-wrap headers extending through the Shield.

\subsection{Software Used}

\section{Proteus Simulator}

Proteus 8 is one of the best simulation software for various circuit designs of microcontroller [9][12]. It has almost all microcontrollers and electronic components readily available in it and hence it is widely used simulator. It can be used to test programs and embedded designs for electronics before actual hardware testing. The simulation of programming of microcontroller can also be done in Proteus. Simulation avoids the risk of damaging hardware due to wrong design.

The following tools were also used to come up web part of the project; 
International Journal of Computer Science, Engineering and Information Technology (IJCSEIT), Vol.11, No.1/2/3/4/5/6, December 2021

HTML

HTML (Hypertext Markup Language) is the fundamental technology used to define the structure of a webpage [11][13]. HTML is used to specify whether your web content should be recognized as a paragraph, list, heading, link, image, multimedia player, form, tables among others.

\section{Cascading Style Sheets (CSS)}

The CSS is a style-sheet language used to describe the presentation of a document written in HTML or XML (including XML dialects such as SVG or XHTML). CSS describes how elements should be rendered on screen, on paper, in speech, or on other media.

\section{JavaScript}

JavaScript is a programming language that adds interactivity to your website (for example: games, responses when buttons are pressed or data entered in forms, dynamic styling, and animation) [14][15].

\section{JQuery}

JQuery is a cross-platform JavaScript library designed to simplify the client-side scripting of HTML. It is free, open-source software. JQuery's syntax is designed to make it easier to navigate a document, select DOM elements, create animations, handle events, and develop Ajax applications. JQuery also provides capabilities for developers to create plug-ins on top of the JavaScript library.

\section{Bootstrap}

Bootstrap is the most popular HTML, CSS, and JS framework for developing responsive, mobile first projects on the web. Bootstrap makes front-end web development faster and easier. It's made for folks of all skill levels, devices of all shapes, and projects of all sizes. Bootstrap is open source. It's hosted, developed, and maintained on GitHub [16].

\section{$M y S Q L$}

MySQL is the most popular Open Source Relational Database Management System. MySQL is one of the best RDBMS being used for developing web-based software applications. It is used to store information in a database.

\section{Hypertext Preprocessor (PHP)}

The PHP Hypertext Preprocessor (PHP) is a programming language that allows web developers to create dynamic content that interacts with databases. PHP is basically used for developing web based software applications.

\section{Structured Query Language (SQL)}

The Structured Query Language is a standardized programming language used for managing relational databases and performing various operations on the data in them. SQL is regularly used by database administrators, as well as by developers writing data integration scripts [13]16]. 
International Journal of Computer Science, Engineering and Information Technology (IJCSEIT), Vol.11, No.1/2/3/4/5/6, December 2021

\section{RESULTS AND DISCUSSION}

\subsection{System Testing, Verification, Validation and Evaluation}

The system has been verified and tested at system integration and whole system testing. The system modules are able to communicate among themselves reliably. The moisture sensors send the specified data to the micro-controller, which interprets and the system is able to perform based on the command signals being input through the web monitoring and control system.

The hardware is interfaced with all the sensors in the board. The hardware components include the microcontroller, relay, ADC converter, Ethernet shield and all the sensors interfaced. The board is inserted with a router which is used to communicate with the owner and the recorded values. The output shown below denotes soil moisture condition. The second result is the output from the web Application that is developed in the computer that determines moisture levels. It could monitor and control irrigation based on the user commands given via the web monitor and controller. These commands include the one for putting off and putting on the pump and these operations were all observed to be working normally in the final evaluation process.

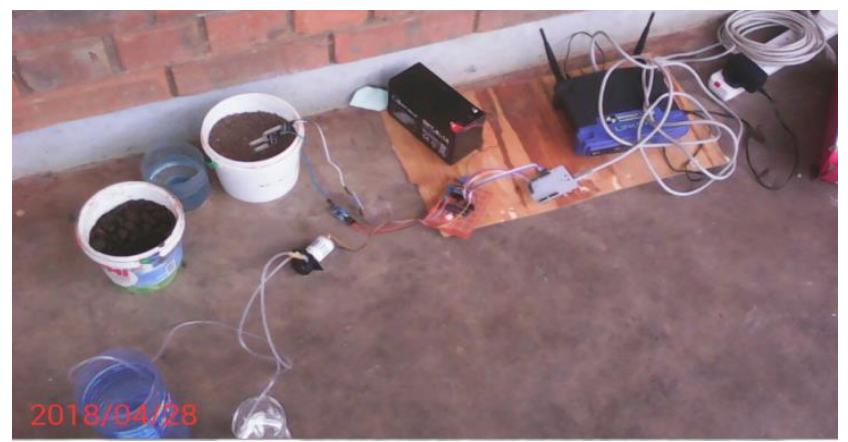

WEB BASED IRRIGATION CONTROLLER

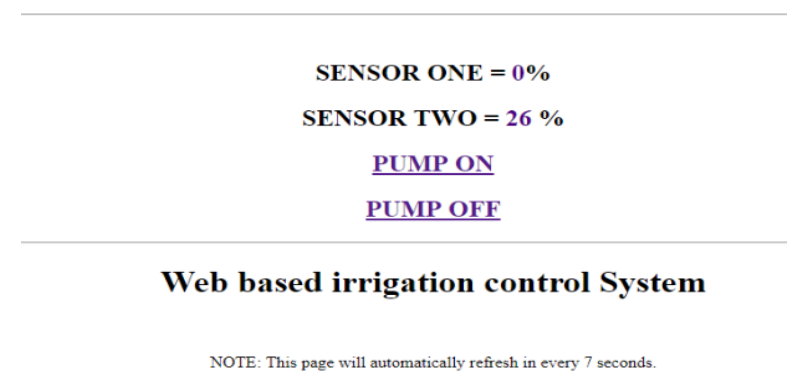

Figure 3. The Monitoring and Control System

\subsection{Limitations in the Developed System}

The system was developed, tested and validated for a given setting of an experiment and seemed to be perfect. However, its specifications are likely to have some limitations depending on the size of the garden versus the number and cost of the sensors. The type of soil also needed to be varied for the proper testing on the accuracy of the sensors which was not captured by the experiment. Specifying the type of crop that may need a particular moisture level could be beyond the working of the system. Some crops for example, rice, require higher levels of moisture than what the system may recommend. 
International Journal of Computer Science, Engineering and Information Technology (IJCSEIT), Vol.11, No.1/2/3/4/5/6, December 2021

\section{FUTURE WORK FOR IMPROVEMENT \& CONCLUSION}

The system has been tested, validated and proven to work and it can now be used for irrigating and by any user. The system as a whole has achieved the main objective, which is a web-based irrigation monitoring and control system. Basing on the design of the system, this system can be set up to work in any farm. The system at hand is fully operational and its guidelines on future usage are provided in the recommendation. This system shall help minimize the errors that could can encountered by the farmer.

For future developments it can be enhanced by developing this system for large acreage of land. Also the system can be integrated to check the quality of the soil and the growth of crop in each soil. The sensors and microcontroller are successfully interfaced and wireless communication is achieved between various nodes. All observations and experimental tests prove that this project is a better solution to irrigation problems. Implementation of such a system in the field can definitely help to improve the yield of the crops and overall production.

\section{REFERENCES}

[1] D. N. Suma, S. R. Samson, S. Saranya, G. Shanmugapriya, and R. Subhashri, "IOT Based Smart Agriculture Monitoring System," Int. J. Recent Innov. Trends Comput. Commun., vol. 5, no. 2, pp. 177-181, 2017.

[2] T. Yamazaki and K. Miyakawa, "Soil Moisture Sensing Experiments for Water Management in Pear Fields," in Proceedings of the 6th International Conference on Informatics, Environment, Energy and Applications, 2017, pp. 56-59.

[3] C. Angel and S. Asha, "A study on developing a smart environment in agricultural irrigation technique," Int. J. Ambient Syst. Appl., vol. 3, no. 2, p. 3, 2015.

[4] Y. Kim, R. G. Evans, and W. M. Iversen, "Remote sensing and control of an irrigation system using a distributed wireless sensor network," IEEE Trans. Instrum. Meas., vol. 57, no. 7, pp. 1379-1387, 2008.

[5] P. G. Student, "AN IoT BASED SMART IRRIGATION SYSTEM."

[6] H. Heriyanto et al., "Water supply pumping control system using PWM based on precision agriculture principles [J]," IAEJ, vol. 25, no. 2, pp. 1-8, 2016.

[7] A. A. A. Derbala, "Development and evaluation of mobile drip irrigation with center pivot irrigation machines," 2003.

[8] N. Barroca, L. M. Borges, F. J. Velez, F. Monteiro, M. Górski, and J. Castro-Gomes, "Wireless sensor networks for temperature and humidity monitoring within concrete structures," Constr. Build. Mater., vol. 40, 2013.

[9] R. Suresh, S. Gopinath, K. Govindaraju, T. Devika, and N. S. Vanitha, "GSM based automated irrigation control using raingun irrigation system," Int. J. Adv. Res. Comput. Commun. Eng., vol. 3 , no. 2, pp. 5654-5657, 2014.

[10] N. Philipova, O. Nicheva, V. Kazandjiev, and M. Chilikova-Lubomirova, "A computer program for drip irrigation system design for small plots," J. Theor. Appl. Mech., vol. 42, no. 4, pp. 3-18, 2012

[11] D. S. Pavithra and M. S. Srinath, "GSM based automatic irrigation control system for efficient use of resources and crop planning by using an Android mobile," IOSR J. Mech. Civ. Eng. e-ISSN, pp. 1684-2278, 2014.

[12] S. R. N. Reddy, "Design of remote monitoring and control system with automatic irrigation system using GSM-bluetooth,” Int. J. Comput. Appl., vol. 47, no. 12, 2012.

[13] V. N. R. Gunturi, "Micro controller based automatic plant irrigation system," Int. J. Adv. Res. Technol., vol. 2, no. 4, pp. 194-198, 2013.

[14] L. Gao, M. Zhang, and G. Chen, "An Intelligent Irrigation System Based on Wireless Sensor Network and Fuzzy Control,” JNW, vol. 8, no. 5, pp. 1080-1087, 2013.

[15] W. A. Dorigo et al., "Evaluation of the ESA CCI soil moisture product using ground-based observations," Remote Sens. Environ., vol. 162, pp. 380-395, 2015.

[16] C. P. Lam, Computational intelligence for functional testing. IGI Global, 2010. 
International Journal of Computer Science, Engineering and Information Technology (IJCSEIT), Vol.11, No.1/2/3/4/5/6, December 2021

\section{AUTHORS}

Mr. Wodadaya Nafutali graduated from Busitema University with a Bachelor's degree in Computer Engineering. Nafutali has deep knowledge and interest in network, hardware Engineering and software development.

Dr. Twaibu Semwogerere holds a Bachelor of Science Education degree (Mathematics), Master of Science degree (Applied Mathematics) and a PhD in Mechanical Engineering (Engineering Mathematics) of Makerere University, Kampala, Uganda. He has a work experience of over 24 years in colleges and university teaching. Published several papers. He is currently an Associate Professor in the Faculty of Engineering, Busitema University.

Mr. Matovu Davis is a Lecturer at the department of Computer Engineering, He holds BSc \& MSc in Computer Systems and Networks Engineering from KHNURE, He is currently pursuing a PhD at MMUST-Kenya, his research interests are in cyber security and Internet of things.

Mr. Lusiba Badru is a Lecturer at the Department of Computer Engineering, He holds BSc \& MSc in Computer Science from Gajah Mada University, Indonesia. He is currently pursuing a PhD at MMUSTKenya, his research interests are in Application of ICT in Agriculture and Land Use.

Dr. Gilbert Gilibrays Ocen is a Seniour Lecturer at the department of Computer Engineering, He holds BSc. (Hons) in Computer Engineering from KHNURE, MSc. Information Technology- from CUU and a $\mathrm{PhD}$ at MMUST-Kenya in Information Systems. He has deep research interest in information and Network security, Cyber-security and Digital Forensics as well as ICT4D. He has supervised over 40 under graduate research projects in his areas of interests. 